\section{La Evaluación Social de Proyectos}

Turísticos: un enfoque simplificado con

\section{criterios de productividad}

The Social Assessment of Tourism Projects:
a simplified productivity criterion approach

Alfredo Ascanio

RESUMEN: La metodología de evaluación social de proyectos turísticos es una guía que pretende solamente ordenar los proyectos de inversión, según lo que los economistas denominan la productividad social marginal de los recursos que requieren los proyectos turísticos. Esta evaluación es un complemento de la evaluación privada y social de proyectos, realizada con los criterios del Valor Presente Neto (VAN) y la Tasa Interna de Retorno (TIR). La jerarquización de los proyectos turísticos, aplicando coeficientes de productividad a la evaluación privada y social, permite optar por aquellos proyectos que producen los mejores impactos para la sociedad como un todo, y esto es relevante especialmente en los países emergentes con escasez de recursos para el desarrollo y que desean aplicar políticas de programación de inversiones.

PALABRAS CLAVE: turismo y economía; proyectos turísticos; evaluación hotelera; criterio social; productividad.

ABSTRACT: The methodology for social assessment of tourism projects is a guide designed to simply outline investment projects, according to what economists call marginal social productivity of the resources required by tourism projects. This assessment serves as a complement to the private \& social assessment of projects, made according to Net Present Value (NPV) and Internal Rate of Return (IRR) criteria. The hierarchization of tourism

1. Economista venezolano. Profesor titular de la Universidad Simón Bolívar. Su correo electrónico es: ajascanio@cantv.net y su hoja web es: http://www.geocities.com/aascanio2000/Mi_pagina.html. projects by applying productivity coefficients to private \& social assessment enables one to opt for projects having the best impacts on society at large, and this is particularly valuable in emerging countries lacking development resources and willing to apply investment-programming policies.

KEYWORDS: tourism and economy; tourism projects; hotel assessment; social criterion; productivity.

\section{Introducción}

Los impactos de los proyectos de inversión en economías emergentes son difíciles de evaluar debido básicamente al hecho de que el sistema de precios no reflejan los costos o valores reales, economías de escala, economías y deseconomías externas y los problemas de la distribución de los ingresos. A menudo, los métodos que se sugieren no se pueden respaldar con datos estadísticos fuertes y el tiempo también es una limitante.

Para realizar las evaluaciones sociales de proyectos de inversión se requiere utilizar los llamados precios de referencia, los cuales son difíciles de estimar y también, como son diferentes a los precios observados, las entidades decisorias desconfían de los ajustes realizados.

Por todas las razones anteriores algunos analistas han sugerido métodos evaluativos más pragmáticos, que aunque se basan en los marcos referenciales teóricos, proporcionan una manera de realizar la mínima evaluación con menos complejidad. En este sentido, por ejemplo, los trabajos de Andre Bussery sugiere evaluar un proyecto tomando en cuenta los impactos de una inversión en las empresas relacionadas antes y después del proyecto e incluso las consecuencias en las finanzas públicas (Bussery, 1973: 25). Es interesante también darse cuenta que la mayoría de los autores recomiendan prudencia y discernimiento, al aplicar estos esquemas de evaluación, debido a las dificultades teóricas e incluso operativas.

La asignación de recursos en la economía es una tarea compleja, sin embargo es necesario planificar esta tarea, bien sea con procedimientos normativos como el Análisis Costo-Beneficio, o bien mediante métodos descriptivos y más simples como el que aparece en seguida. A veces es mejor aplicar un método sistemático y objetivo a fin de sustituir las decisiones intuitivas.

Una aproximación muy útil aplicada a los proyectos turísticos la encontramos en el Cap. 5 del libro de Edgar Alfonso Hernández Díaz (1985). Allí se trata la evaluación social, que a diferencia de la evaluación privada puede arrojar diferentes resultados, debido a que no toda inversión de capital tiene la virtud de utilizar 
racionalmente el ambiente físico donde se localiza y menos aun fomentar la justa distribución de la riqueza generada.

En la metodología propuesta por Hernández, los ingresos de un proyecto hotelero para el inversionista privado se diferencian de los ingresos como generadores de riqueza social (PIB), pues para el inversionista sus ingresos sólo están determinados por la suma de las depreciaciones de los activos fijos y las amortizaciones de los activos intangibles, más su flujo neto de caja; pero para la sociedad estos ingresos vienen dados por los rubros que forman los valores agregados, es decir: sueldos y salarios, depreciaciones, los gastos financieros, los impuestos indirectos y el flujo neto para el empresario, entre otros.

En cuanto al plan de inversión también se hace una diferencia, pues el empresario sólo toma en consideración el capital de riesgo invertido por él; y la sociedad toma en consideración todas las inversiones del proyecto, bien sea que provengan de préstamos nacionales o bien de fondos propios. Luego, en esta metodología el flujo de caja social (PIB) se descuenta con una tasa social que define el organismo de planificación del país donde se realiza la evaluación. En el ejemplo de Hernández, se aclara que los precios del mercado no fueron corregidos con los precios sombras o sociales, pues ello implicaría conocer todos los costos de oportunidad de los factores de la producción y además desagregar los ingresos del hotel, según se capte turismo doméstico o internacional, debido al precio de la divisa con relación a la moneda nacional. En este caso, las tasas de descuento tanto para la evaluación privada y social son relevantes ya que ello influye definitivamente en la decisión final. (Hernández, 1985: 174).

En algunos textos de ingeniería económica aparece siempre un capítulo para tratar el tema del análisis de proyectos públicos, bien sea aplicando los conceptos de análisis costo-beneficio o bien costo-efectividad (Riggs, 1977: 13). De nuevo, en estos textos se señala que la tasa de descuento es un problema ampliamente debatido, ya que: para que los proyectossean aceptados o rechazados ello depende de la tasa de descuento seleccionada. El costo de capital para el gobierno varía ampliamente según las condiciones económicas vigentes y el plazo de los financiamientos que logre conseguir; pero como los bonos del gobierno se consideran, en general, de bajo riesgo, la tasa mínima de descuento puede ser aquella que corresponda a la tasa correspondiente de dichos bonos. La tasa social de descuento se puede estimar en base al costo del endeudamiento del gobierno; por ejemplo, en USA y durante la década de los años 70, esta tasa se había estimado en 10\% (Riggs, 1977: 477); es decir, que todo proyecto público que rindiera una tasa menor, digamos el $8 \%$, era entonces rechazado, o por lo menos no recibía beneficios y subsidios del Estado.
La teoría económica de la empresa nos señala que el criterio general para asignar prelaciones a proyectos de inversión, desde el punto de vista de un inversionista privado, consiste en conocer cuál es el aumento que se obtiene en el producto, como consecuencia de añadir una cantidad determinada del factor más exiguo, que en nuestros países emergentes es el capital y especialmente las divisas. Los economistas se refieren a este criterio con el nombre de la productividad marginal (o incremental) del recurso más escaso (Klein, 1961: 11). No obstante, la sociedad como un todo también desea promover proyectos, de manera tal que cuando se realice una inversión neta se obtenga un producto interno bruto (PIB) más elevado, se logre un incremento del empleo, una mejor distribución de los ingresos y una balanza de pago mejorada; y en el caso de los proyectos turísticos, no se impacte negativamente al medio natural que es su razón de ser. De esta manera se determina, igualmente, el valor social de una inversión estratégica.

El problema que se va a plantear en este artículo es el siguiente: ¿qué alternativa de inversión turística contribuye más al desarrollo económico, es decir al máximo beneficio económico-social?

La regla general para un desarrollo turístico adecuado, en su aspecto formal, nos señala que se debe invertir en aquellos proyectos en los cuales el empleo de un capital dado ofrece la productividad social más elevada. La aplicación de este principio es difícil, debido a la dinámica del proceso de inversión, que es un proceso orgánico por naturaleza y produce amplias repercusiones sociales e institucionales; y también porque algunos objetivos que deseamos lograr con los proyectos, pueden ser incompatibles, como por ejemplo, la necesidad de emplear un número elevado de trabajadores, frente a la importancia de alcanzar una alta productividad laboral.

Como las metas del desarrollo se fundamentan en las aspiraciones nacionales por alcanzar una vida más decorosa o más digna, las fuerzas sociales que determinan la marcha del desarrollo tienen gran importancia, ya que son las promotoras del progreso.

Para lograr que el PIB crezca, por lo menos deberíamos invertir capitales en una relación de 3 a 1. A veces se señala que ese coeficiente de capital, en los países emergentes, debería ser mucho mayor, pues seguramente es necesario efectuar inversiones básicas en infraestructura turística, por ejemplo, para que los visitantes temporales puedan llegar sin dificultades al sitio turístico (vías, aeropuertos, puertos), puedan contar con electricidad, agua, telecomunicaciones, drenajes, alcantarillado, viviendas para los trabajadores, etc...

Así pues, la composición del programa de inversión turística, influye sobre la magnitud del coeficiente de capital de un país determinado, pues depende 
también de la tecnología que se quiera adoptar. No es lo mismo, por ejemplo, la promoción de un conjunto de hoteles lujosos de elevada inversión por cuarto, que tomar la decisión de realizar un conjunto de cabañas mimetizadas en el ambiente bucólico de la propia naturaleza, donde lo que se desea privilegiar es una armonía entre el paisaje y el alojamiento confortable, pero de bajo costo de inversión. En resumen, los proyectos de inversión deben adaptarse, en cada caso, al patrón general del desarrollo y concordar con la política establecida para su adecuada promoción.

\section{Proyectos Turísticos e Inversiones}

\section{La evaluación del sistema}

La expansión del turismo depende, sobre todo, de la magnitud de los mercados que se satisfacen con determinados "productos". El comportamiento de los turistas determina, en última instancia, el patrón de la economía turística; al igual que la coordinación de los esfuerzos locales encaminados a lograr una mayor productividad en su conjunto. De allí surge la necesidad de evaluar los proyectos de inversión turística no de modo aislado, sino en lo posible conjuntamente con proyectos complementarios. En el caso del turismo, además de las inversiones en infraestructura, es necesario asegurar una planta recreativa suplementaria en armonía con la planta de alojamiento, pues el turista no reside sino más bien se aloja con la finalidad de recrearse en el medio geográfico seleccionado.

\section{Otros elementos del sistema}

Otro de los problemas que es necesario afrontar es la preparación de personal calificado para poder realizar el trabajo en las empresas turísticas. Por eso, un programa de promoción turística debe realizar, simultáneamente, dos cuestiones claves: fomentar el adiestramiento de la población que se desea reclutar y facilitar su movilidad con un criterio selectivo.

El coeficiente de capital por persona empleada en la hotelería, debido a que sus procedimientos de trabajo se encuentran mundialmente estandarizados, puede ser estimado según la categoría del hotel, en inversiones que van desde US $\$ 30.000$ dólares por habitación (para 0,50 persona por habitación) hasta US\$150.000 a US $\$ 200.000$ dólares por habitación en la hotelería de lujo (para un estimado de
1 persona por habitación). Entonces el capital por persona empleada, puede estar en un extremo de US\$ 15.000 por persona empleada hasta US $\$ 200.000$ por persona empleada. Es obvio que la inversión en alojamientos más sencillos, como las posadas turísticas, asegurarían una inversión por empleado mucho más baja que la que requiere un complejo turístico integral.

Otro asunto importante es eludir la dependencia excesiva de productos importados para poder operar el centro turístico, ya que existe una escasez de divisas y es necesario ahorrarlas e incluso generarlas. Claro está, que una limitante puede ser la calidad de los materiales utilizados tanto para invertir como para la operación hotelera.

Igualmente, el mercado doméstico e internacional de turistas debe estar en condiciones de absorber todos los servicios turísticos promovidos. Un programa de desarrollo turístico debe asegurar que las inversiones no sobrepasen las necesidades del mercado, para que las empresas puedan trabajar a una capacidad adecuada y se logre un punto de equilibrio óptimo.

\section{El interés privado versus el interés público}

En el caso del turismo se debe tener en cuenta que la empresa turística no es sólo un negocio basado en el principio de la obtención de una rentabilidad mayor que otras alternativas, sino, sobre todo, ella es una institución subordinada a los intereses económicos y sociales de la comunidad donde se inserta. Es de esperar que el empresario privado tenga que otorgar prioridad a un proyecto turístico cuya seguridad y rentabilidad sea la mayor, en relación a otras oportunidades. Por eso, el empresario necesita un clima general favorable, unos mercados asegurados, una adecuada infraestructura, una perspectiva de rendimiento, un recurso humano productivo, seguridad jurídica y una estructura de precios relativamente estable.

Las inversiones gubernamentales, para asegurar adecuados servicios públicos en la comunidad receptora turística (vivienda, salubridad, educación, seguridad, promoción ambiental y estética), se complementan con las inversiones en infraestructura y con las inversiones privadas en planta turística; $y$ justamente, al existir la inversión pública de soporte, entonces se deben evaluar también los proyectos desde el punto de vista de la sociedad como un todo.

La productividad se acepta como un criterio básico para el éxito de las inversiones, tanto privada como social, pues de lo que se trata es de obtener el máximo producto con una acertada combinación de insumos, para lograr el costo unitario más bajo posible. 
En tanto que el interés dominante del empresario radica en lograr una adecuada utilidad del capital invertido; y recuperar su inversión con los menores riesgos posibles, la preocupación de la sociedad consiste en obtener de la inversión, la mayor utilidad social posible, es decir obtener un elevado PIB y lograr los mejores efectos relacionados con el empleo, la redistribución del ingreso, una balanza de pago equilibrada; y la preservación del medio natural para lograr la sustentabilidad de los proyectos.

El inversionista privado requiere que los proyectos de inversión se elaboren con base en los precios vigentes en el mercado; estos precios, sin embargo, ya incluyen ciertos beneficios o sacrificios sociales, los cuales hay que eliminar de los cálculos, a fin de estimar el beneficio neto para la sociedad.

Los recursos que utiliza un proyecto privado ya producen unos determinados beneficios a la sociedad en su uso actual, antes de que surgiera un nuevo proyecto. El proyecto privado generará valores agregados (sueldos, salarios, prestaciones sociales, interés al capital, renta de la tierra, impuestos indirectos y beneficio empresarial), pero como ya los factores que se van a utilizar, producían valores agregados en usos anteriores, por lo que es necesario ajustar el valor agregado privado, de forma tal que solamente la diferencia entre el costo social de los factores y su precio en el nuevo uso, produzca un beneficio neto a la sociedad.

Para determinar ese beneficio neto, habrá que tomar en cuenta las alteraciones que a causa del proyecto turístico se experimentarán en los impuestos y en los subsidios (impuestos negativos); en el tipo de cambio, pues los costos de importación (incluso del turismo emisivo) o la cuantía de las exportaciones "in-situ" (al llegar los turistas extranjeros), serían subestimados, si el tipo de cambio oficial fuera menor que el valor intrínseco de la moneda extranjera en el país receptor.

$\mathrm{Si}$ no se realizan los ajustes pertinentes, los proyectos que requieran importaciones resultarían demasiados favorables y los proyectos con excedentes de exportaciones parecerían demasiado desfavorables. En el caso de países con una paridad cambiaría en equilibrio con el dólar, este factor no tiene mayor significación, pero si en aquellos países donde el tipo de cambio puede favorecer o no tanto a las importaciones como a las exportaciones.

No cabe duda que estos conceptos son difíciles de aplicar; y casi nunca se logra un cálculo exacto. Lo que si pareciera importante es estimar los desequilibrios más relevantes que puedan causar discrepancias entre los precios del mercado y los precios sociales reales o de equilibrio. Los efectos pueden ser directos e indirectos. Los indirectos se refieren a los efectos de los valores agregados generados hacia los insumos que consume el proyecto y hacia los canales de comercialización, ya que los proveedores de estos bienes y servicios tienen, a su vez, relaciones con otras empresas formando así una cadenas de interrelacionadas de valores agregados.

\section{La decisión con criterios parciales y la experiencia de los expertos}

Estas breves consideraciones nos demuestran que no es posible asignar prelaciones a proyectos turísticos en forma abstracta, esto es, sin que se reconozca la política de desarrollo y el propósito específico de los proyectos a evaluar. Por ello, no es sencillo combinar los criterios parciales, si no está claramente precisado el propósito que se persigue con los proyectos turísticos. A veces estos propósitos mismos no aparecen claramente definidos y muchas veces se suele recurrir a la experticia de peritos en asuntos turísticos, para que opinen sobre cuáles proyectos deben tener prioridad; y cuáles datos sirven para realizar las evaluaciones.

La experiencia tiene un valor extraordinario, pero es necesario asegurarse que el experto tiene una visión holística de los elementos que entran en juego y que están relacionados con el proyecto de inversión que se evalúa. No hay que olvidar también que las opiniones pueden estar inconscientemente predispuestas y que pueden sesgar las decisiones; por ello, es conveniente que la evaluación sea sistemática y lo más objetiva posible, pues la metodología analítica es mucho más segura que el método informal y emotivo.

Se puede trabajar con un conjunto de parámetros, a manera de una base cuantitativa para adoptar decisiones. No obstante, para realizar una evaluación más segura es necesario una muy buena información; y como al seleccionar los datos, se presenta la incertidumbre, habría que recurrir a un método para sondear las opiniones de los expertos acerca de cuáles parámetros pueden utilizarse para lograr una buena estimación; o qué tipo de ajustes habría que introducir, para asegurar, con algún grado de probabilidad subjetiva, que los datos del modelo sean pertinentes. (Reilly, 1969: 122)

El problema que se plantea consiste en conocer qué alternativa de inversión turística contribuye más al desarrollo, o sea a la productividad social marginal de recursos limitados. Los factores de operación que intervienen (es decir, los parámetros que corresponden a la naturaleza del proyecto) son, al menos, los siguientes:

1) el efecto sobre el PIB (el valor agregado directa o indirectamente, ajustado al precio social);

2) el efecto sobre la creación y distribución del ingreso, al precio social, de la población afectada directa e indirectamente;

3) el efecto sobre la balanza de pagos, relacionada con el comercio internacional;

4) los efectos en el medio natural y cultural donde se localiza el proyecto. 
Existen factores limitantes o exógenos al proyecto como son: el ambiente económico, natural, político, social e institucional. A veces existen limitaciones en cuanto a los recursos como los suministros de insumos, la mano de obra y el financiamiento; y también las limitaciones tecnológicas, como las características de los equipos, del proceso constructivo de la organización para generar el proyecto y operarlo.

La naturaleza de un proyecto hotelero, por ejemplo, podría suministrar los datos básicos sobre ventas, insumos intermedios utilizados, valor agregado (sueldos y salarios, prestaciones sociales, intereses, reservas para depreciación, impuestos indirectos y utilidades), como aparece en el siguiente ejemplo:

\section{Millones de US\$}

\begin{tabular}{|c|c|}
\hline & \\
\hline bit & 1,1 \\
\hline & , \\
\hline & 8,5 \\
\hline &, 28 \\
\hline sumos interm & 6,26 \\
\hline .... & 2,43 \\
\hline & 0,61 \\
\hline ......... & 0,4 \\
\hline$\ldots . . .$. & 0,4 \\
\hline (2) & 0,8 \\
\hline ........ & 0,8 \\
\hline$\ldots \ldots \ldots$ & 0,20 \\
\hline & 0,20 \\
\hline & 0,4 \\
\hline & 15,70 \\
\hline os y prestaciones......... & 5,08 \\
\hline 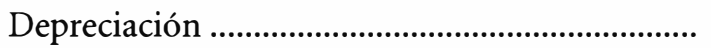 & 2,12 \\
\hline . & 0,79 \\
\hline 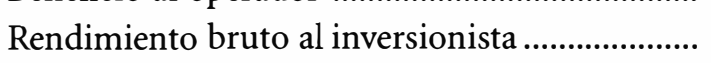 & 4,96 \\
\hline ........ & 1,7 \\
\hline & 1,0 \\
\hline
\end{tabular}

Fuente: Figuerola (1991). Los datos del caso se han dividido entre 130 para ilustrar la metodología con cifras más pequeñas.

\section{Evaluación del Proyecto Hotelero}

\section{El procedimiento metodológico}

Este proyecto se refiere a un hotel de lujo ( 5 estrellas) de 330 habitaciones, es decir 660 plazas-camas (equivalente a 240.900 plazas-camas al año al $100 \%$ de capacidad), con un volumen de construcción de $29.679 \mathrm{~m}^{2}$ y con un total de suelo previsto de $135.000 \mathrm{~m}^{2}$ para una inversión estimada en activos fijos de 29,61 millones de unidades monetarias, lo cual podría ser financiado el $40 \%$ con crédito bancario. El 20\% de los activos fijos se estimó como capital circulante y es igual a 5,92 millones.

El proyecto tendría un potencial de turistas a captar de 22.631, de los cuales un $60 \%$ serían nacionales (muchos de ellos captados del turismo nacional emisivo hacia Miami); y un $40 \%$ extranjeros, con una estancia media de 6,92 noches.

Se estimó vender el $65 \%$ de las plazas-camas (156.585) con un ratio estanciahabitación igual a 1,91 (venta igual a 81.906 habitaciones al año). De la venta total, el $95,4 \%$ serían habitaciones dobles y el $4,6 \%$ habitaciones simples. El potencial de ingresos crecería a una tasa media del $4 \%$ al año; y se espera que las tarifas se incrementarían en una media del $6 \%$ por año, al igual que los costos.

Para evaluar este proyecto, desde el punto de vista social, se requiere ordenar algunos de sus datos; por ejemplo, la inversión en activos fijos y activo circulante como sigue:

a) Terreno, construcción, equipamiento y otros activos fijos ............................................. 29,61

b) Inventarios y materiales auxiliares, así como transacciones de compra y venta 5,92

\section{TOTAL}

El financiamiento con capital propio se estimó en un 60\% del total, es decir 21,32 millones, y el resto, es decir el $40 \%$, sería financiado con capital crédito, como fue señalado.

De la inversión anterior, solamente el equipamiento del hotel será importado por no fabricarse en el país y por un valor total estimado en 7,62 millones.

Las ventas, después de la realización completa del proyecto, se estimaron, con base en los precios vigentes, en: 21,96 millones anuales; y el rendimiento bruto del inversionista se estimó en 4,96 ; esto corresponde a un $23 \%$ sobre las ventas, y a un $23 \%$ sobre el capital propio invertido. 


\section{Tomando en cuenta la inversión total esta se detalla en seguida:}
a) Terrenos . 2,07 millones
b) Construcciones .
17,44
c) Equipamiento importado 7,62
d) Equipamiento nacional y otros 2,48
e) Capital de trabajo 5,92
TOTAL

El hotel ofrecería empleo a 264 personas, de esta manera:

a) Trabajadores permanentes especializados ........ 155

b) Trabajadores semiespecializados o no especializados

c) Empleados técnicos y administrativos

TOTAL

Los salarios de base serían los vigentes en el área de trabajo de estos negocios, así como las prestaciones sociales; por lo que el costo anual se estimó en 5,08 millones.

Las materias primas para alimentación, mantenimiento y servicios locales serían de origen nacional. Las materias importadas básicamente serían las bebidas y algunos otros productos importados que no existen en el país, por lo que se previó que la distribución de los llamados insumos intermedios, podría ser como sigue:

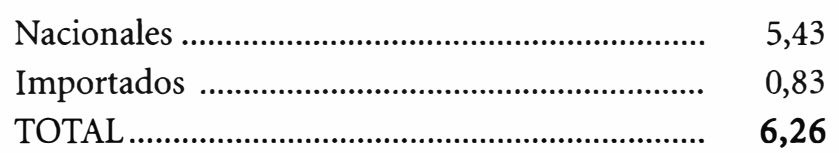

El hotel trabajaría tres turnos en los horarios normales de la hotelería; y comenzaría operando al $65 \%$ de la capacidad instalada, para luego llegar a una utilización óptima del 74,6\% al 5to año de operación.

El presupuesto de los gastos anuales del hotel, incluidas las utilidades calculadas sería como sigue:
Insumos intermedios

Materia primas, materiales y servicios

comprados

Valor agregado

Sueldos, salarios y prestaciones .......................... 5,08

Depreciación .................................................. 2,12

Beneficio al operador ...................................... $\quad 0,79$

Impuesto indirectos .......................................... 1,74

Costo de servicios financieros............................ 1,01

Rendimiento bruto del inversionista ................. $\quad 4,96$

Valor de las ventas o producción del servicio .... 21,96

\section{La evaluación social como criterio complementario al criterio privado}

La evaluación privada de este proyecto hotelero es obvia, pues el inversionista privado erogaría como inversión, y durante dos años, 21,3 que a valor presente descontado con la tasa del $15 \%$ sería igual a 17,4 ; y a su vez, los valores descontados de sus beneficios netos suman 24,4, lo que arroja un Valor Actual Neto de 7,0 y una tasa Interna de retorno del $\mathbf{2 8} \%$.

No obstante, la evaluación social del proyecto, es decir los beneficios para la comunidad como un todo, se estiman con otros elementos de juicio. Primero, se calculan los efectos del proyecto hotelero en el PIB (el total de los valores agregados brutos en la economía nacional); segundo, se consideran todas las inversiones, y no sólo aquellas relacionadas con el capital de riesgo; tercero, se estiman los efectos sobre el empleo y la distribución del ingreso; cuarto, se estiman los efectos sobre la balanza de pagos; y quinto, se estiman los efectos ambientales; y si existen elementos restrictivos serios que dificulten la inversión y operación hotelera.

\section{1) Efecto sobre el producto nacional}

El valor agregado calculado en el proyecto estimado en 15,7 no refleja , en rigor, el beneficio que este hotel nuevo reportará a la sociedad; el proyecto empleará factores productivos, que ya en su utilización actual contribuyen, de alguna manera, con ciertas cantidades al producto nacional ( no son factores ociosos pues están 
ocupados); así pues, el beneficio social que podemos atribuir al proyecto hotelero, lo constituye únicamente el aumento que se obtenga en tales factores, como consecuencia de la ejecución del mismo. Los conceptos que se verían afectados en este sentido, y para este caso, son los siguientes:

a) Impuestos a la importación: una vez en plena producción, el nuevo proyecto hotelero aspira a captar turismo nacional en un $60 \%$, el cual en su mayoría, y por falta de una política de turismo doméstico, viajan al exterior y allí realizan su actividad turística, cuyo valor se estima en 10,84 millones; considerando que los viajeros nacionales pagan una tasa media de impuesto de salida del $5 \%$ ad valorem, el nuevo hotel perjudicaría al fisco en una cantidad igual a 0,54 millones; por otro lado la nueva empresa importará bebidas por el orden de los 0,83 millones, a los cuales conviene en este caso aplicar una tasa media del $20 \%$ ad valorem, es decir 0,17 millones que compensa en parte el impacto fiscal anterior ; y también el hotel importará el equipamiento por valor de 7,62 millones, con una tasa impositiva ad valorem del $20 \%$, es decir 1,52 millones, quedando entonces una entrada neta de impuestos fiscal de sólo 1,15 millones.

b) Sueldos y salarios: el ingreso que anualmente percibe en la actualidad la mano de obra que sería reclutada por el hotel (sueldos, salarios y prestaciones), y que proceden de otras actividades y probablemente de otros lugares del país, se estima en 2,03 millones (un 40\% de la remuneración que cancelará el proyecto).

c) Intereses y utilidades: se estima que el capital total que empleará el proyecto para su realización (capital fijo y circulante) de 35,53 unidades monetarias, debe estar rindiendo actualmente un interés anual neto del $12 \%$, lo cual corresponde a un ingreso anual de 4,26 millones (como el costo de oportunidad del dinero es igual al $12 \%$, por eso los proyectistas descuentan con una tasa del $15 \%$ como Tasa Mínima Atractiva de Rendimiento).

Así pues, para llegar al beneficio que de modo directo puede lograr la realización del proyecto hotelero, hay que reducir el valor agregado estimado con anterioridad (de 15,7), tomando en cuenta los siguientes elementos:

1) Impuestos de importación ajustados

1,15 millones

2) Sueldos, salarios y prestaciones que se perciben en la actualidad

2,03 millones

3) Intereses y utilidades del capital que será utilizado.

4,26 millones

TOTAL

7,44 millones
En resumen tenemos que restar del valor agregado del proyecto, una cantidad total estimada en 7,44 millones para obtener un valor agregado neto igual a 8,26 millones que podría ser considera la contribución directa ajustada al PIB de este nuevo hotel.

d) Impactos indirectos: los principales efectos indirectos serían originados por la actividad constructiva utilizando materiales nacionales; y por la ampliación correspondiente de las actividades de los proveedores de la industria de la construcción y otros proveedores locales de insumos intermedios y servicios. No obstante, estas repercusiones son más difíciles de estimar, si no se cuenta con de una matriz insumo-producto del sector turismo. Con todo, la compra de insumos intermedios nacionales y servicios locales por valor de 5,43 millones, aumenta el valor agregado en las actividades de esos proveedores y contribuye, por esto, al producto nacional de modo indirecto. Estimando que la actividad de que se trata es básicamente el suministro de materias primas alimenticias por valor de 2,43 millones, y considerando que en esa actividad por cada 100 de valor de la producción más o menos el $50 \%$ corresponde al valor agregado, lo anterior supondría que el nuevo hotel induce valor agregado adicional de por lo menos 1,21 millones en sus abastecedores de alimentos que suplen su economato y bodegas; y en el supuesto de que las compras mejoren la utilización de la capacidad instalada de los suplidores de alimentos.

En cuanto a los servicios comprados a otras empresas por valor de 4,85 millones y suponiendo que su relación ventas-valor agregado sea de por lo menos el 70\%, entonces otra cantidad estimada en 3,39 millones se supone que sería el valor agregado adicional de esas actividades de servicios comprados (energía, agua, mantenimiento, seguro, propaganda, comunicaciones, financiación, etc...).En resumen, un valor social agregado indirectamente de 4,61 millones (del cual quizá el $30 \%$ corresponda a sueldos, salarios y prestaciones, o sea 1,38 millones).

e) Repercusiones en otras empresas asociadas: la disponibilidad de un hotel eficiente para alojar turísticas, especialmente visitantes que desean realizar actividades de negocios o de vacaciones a precios convenientes, induce la creación de valores agregados adicionales en otras actividades turísticas ligadas al hotel, como tiendas de artesanías, promotores de excursiones y eventos, etc. Es también difícil estimar esto, pero su influencia en la economía local puede ser relevante, porque se trata de animar al visitante, que al fin busca una actividad recreativa temporal o una actividad de negocio y para ello se decidió a desplazarse al lugar seleccionado. En la metodología que propone Bussery, como fue señalado, se busca la manera de realizar estos cálculos aguas arriba y aguas abajo del proyecto central. 


\section{2) Efecto sobre el empleo y la distribución del ingreso}

Según los datos del proyecto, éste ofrecerá empleo a 264 personas durante todo el año, lo que resulta en un estimado de sueldos, salarios y prestaciones de 5,08; pero como se había estimado, que el costo de oportunidad de este recurso era igual a 2,03 millones, entonces el verdadero aumento del poder de compra de estos empleados es igual a la diferencia, o sea 3,05 millones anuales. Incluyendo los miembros familiares de los empleados, se puede estimar en 924 personas que podrían beneficiarse del proyecto hotelero. $Y$ es posible un efecto indirecto hacia los proveedores más próximos como ya se estimo en 1,38 millones.

En cuanto a las utilidades, se supone que el capital por invertir tiene un rendimiento actual del $12 \%$ (sin contar el impuesto sobre la renta), entonces lo que se puede atribuir al nuevo proyecto corresponde sólo a la diferencia entre la ganancia neta calculada de 4,96 millones, menos el $12 \%$ del capital total invertido de 35,53 millones ( o sea 4,26 millones), lo cual arroja una cifra de sólo 0,70 millones que es la verdadera ganancia o rentabilidad social que se le puede atribuir al capital invertido en el nuevo proyecto.

\section{3) Efecto sobre la balanza de pagos}

En la fase de la construcción de la planta hotelera, tomando en cuenta sus dos etapas anuales, se gastarán divisas para adquirir equipos importados por el orden de los 7,62, pero también se ahorrarán anualmente, después de la construcción del proyecto, divisas por valor de 2,39 millones (10,84 millones de ahorro de divisas menos 8,45 millones de lo que se importará con divisas que saldrán del país), todo lo cual debe ser considerado.

\section{4) Influencias ambientales sobre el éxito del nuevo proyecto}

Como la localización del nuevo hotel será en un lugar donde ya existe un polo de desarrollo turístico con la infraestructura adecuada (es una isla turística en el Caribe), hay que esperar que este ambiente actúe favorablemente sobre el nuevo proyecto. Quizá una posible falla coyuntural de los servicios básicos de luz y agua, se puedan esperar por falta de una planta desalinizadora y debido a las limitaciones de la energía termoeléctrica del lugar. Si los sistemas de drenajes, alcantarillados y recolección de sólidos funcionan adecuadamente y se han aplicado los criterios de capacidad de carga, a fin de no dañar el ambiente natural y cultural, entonces no es necesario evaluar estos asuntos. Pero en aquellos proyectos turísticos que presenten estas fallas, habrá que tomarlas en consideración porque son de vital importancia para el éxito de la iniciativa.

\section{5) Influencia limitativa de los recursos}

Parece que las limitaciones de materias primas, materiales y disponibilidad de trabajadores se puede solucionar sin traumas importantes y sin asegurar planes de contingencia. Un programa de adiestramiento de la empresa es necesario para elevar la calidad de los servicios.

\section{6) Elementos tecnológicos limitativos}

Si los servicios del hotel se ajustan a las normas y especificaciones técnicas y se puede lograr una adecuada productividad operativa, no se prevén dificultades en este aspecto.

\section{La data y los coeficientes para la evaluación privada y social}

Ahora podemos recapitular con un resumen sobre los datos que nos sirven para realizar una evaluación privada y social de este nuevo proyecto hotelero, solamente manejando coeficientes de productividad al usar los recursos; y sin entrar, en los detalles del uso temporal de las inversiones y los flujos de caja, lo cual es necesario hacerlo, si aplicaramos la metodología propuesta por Hernández y que es la manera más conocida de evaluar los modelos proyectados cronológicamente:

(A) Cálculos desde el punto de vista del inversor privado

\begin{tabular}{|c|c|}
\hline ....... & 29,61 \\
\hline b-Capital circulante . & 5,92 \\
\hline 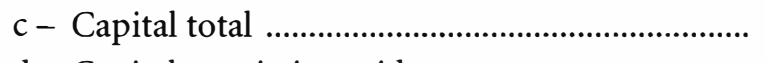 & 35,53 \\
\hline d-Capital propio invertido........ & 21,32 \\
\hline e-Créditos bancarios. & 14,21 \\
\hline 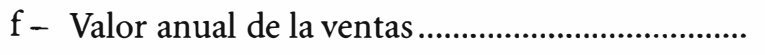 & 21,96 \\
\hline - Insumos nacionales ............... & 5,43 \\
\hline h - Insumos importados .................... & 0,83 \\
\hline - Total insumos intermedios .. & 6,26 \\
\hline
\end{tabular}


j- Valor agregado

$\mathrm{k}$ - Sueldos, salarios y prestaciones .......................... 5,08

1- Intereses o costo financiero .................................. 1,01

$\mathrm{m}$-Reserva para depreciación ................................. 2,12

$\mathrm{n}$ - Impuestos indirectos (excepto ISR) ................... 1,74

o - Utilidad antes de pagar el ISR .............................. $\quad 4,96$

Índices contables desde el punto de vista privado:

1) Rentabilidad de la inversión en activos fijos (o entre a)

2) Rentabilidad del capital total (o entre c) ............ 13,96\%

3) Rentabilidad del capital propio (o entre d) ...... 23,27\%

4) Rotación del capital circulante ( $f$ entre b) ........ 3,71 veces

5) Rotación del capital total (f entre c) ................. 0,62 veces

6) Inversión por \$ de sueldos, salarios y prestaciones (a entre $\mathrm{k}$ )

7) Valor de las ventas por $\$$ del capital invertido (f entre a)

8) Valor de las ventas por $\$$ de sueldos, salarios y prestaciones ( $\mathrm{f}$ entre $\mathrm{k}$ )

9) Valor agregado por $\$$ de sueldos, salarios y prestaciones ( $\mathrm{j}$ entre $\mathrm{k}$ )

10) Utilidad por \$ del valor de las ventas (o entre $\mathrm{f}$ )

(B) Cálculos desde el punto de vista social

a - Inversión en capital fijo...

b - Capital total empleado por el proyecto

c - Valor social agregado directamente...

8,26

$\mathrm{d}$ - Valor social agregado indirectamente

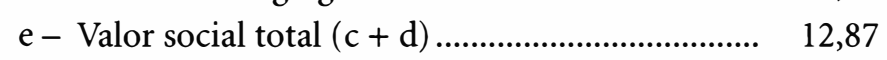

$\mathrm{f}$ - Sueldos, salarios y prestaciones sociales generados directamente

g- Sueldos, salarios y prestaciones sociales generados indirectamente. h - Sumatoria de $f+g$

i - Personal técnico y administrativo

j- Trabajadores especializados .

$\mathrm{k}$ - Trabajadores semicalificados y no especializados.

$1-$ Total $\mathrm{i}+\mathrm{j}+\mathrm{k}$

$\mathrm{m}$ - Valor de divisas para la importación de equipos.

n - Ahorro anual de divisas cuando el hotel esté en operación .

o - Utilidad (rendimiento social del capital) ...........

Índices desde el punto de vista social

1) Rentabilidad social de la inversión:

a. Valor social agregado directamente por $\$$ invertido (c entre a)

b. Valor social agregado directa e indirectamente por $\$$ invertido (e entre a) ...

c. Valor social agregado directamente por $\$$ de capital total (c entre b)

2) Contribución al empleo y distribución de ingresos:

a. Aumento anual en sueldos, salarios y prestaciones, generados directamente por el proyecto y por $\$$ invertido (f entre a) ............

b. Sueldos, salarios y prestaciones, generados indirectamente por $\$$ invertido ( $g$ entre a)...

c. Aumentos anuales en sueldos, salarios y prestaciones, generados directamente por persona ocupada (f entre $\mathrm{l}$ )

0,01 millones

d. Inversión por persona ocupada (a entre l) ... 0,11 millones

e. Aumento en sueldos, salarios y prestaciones, generados directamente por $\$$ de utilidad social ( $\mathrm{f}$ entre o) 
3) Efecto sobre la balanza de pagos:

a. Valor de divisas necesarias para la importación de equipos por \$ invertido ( $m$ entre a)

b. Ahorro anual de divisas cuando el hotel esté en operación, por \$ invertido ( $\mathrm{n}$ entre a) $\quad 0,08$

c. Ahorro anual de divisas, cuando el hotel esté en operación, por \$ gastado para la importación de equipos ( $\mathrm{n}$ entre $\mathrm{m}$ )

\section{Comentario Final}

En una escala del 0,0 al 1,0 estos coeficientes pueden representarse en forma gráfica para ayudar a realizar una comparación entre proyectos turísticos en un programa determinado y para una localidad específica. La idea central consiste en poder jerarquizar los proyectos, según su contribución social, y asegurar que los que presenten mayores impactos favorables, puedan recibir los incentivos adecuados para su promoción y desarrollo; ya que habrán algunos proyectos que contribuirían, más que otros, al PIB por unidad de capital invertido y entonces tendrían mayores impactos en el empleo, la distribución de ingresos, la balanza de pagos y la preservación del medio natural.

Como son varios los coeficientes calculados y unos pueden aparecer mejores que otros, se trata entonces de averiguar si las diferencias entre los proyectos turísticos competitivos es suficientemente significativa para poder optar por un proyecto u otro. Esta es justamente la responsabilidad de quien tiene que diseñar una mejor política de inversión de proyectos para el desarrollo turístico.

La metodología de evaluación social de proyectos turísticos es una guía que pretende ordenar los proyectos de inversión, según lo que los economistas denominan la productividad social marginal de los recursos que requieren los proyectos turísticos. Lo más conveniente es que cada proyecto sea primero evaluado desde el punto de vista del inversionista privado, y observar si pasan prueba las pruebas con el Valor Presente Neto (VAN) y con la Tasa Interna de Retorno (TIR); luego, esos proyectos se deben también jerarquizar según los coeficientes de la evaluación social. El objetivo final es poder optar por aquellos proyectos que producen los mejores impactos para la sociedad como un todo y que además sean buenas inversiones privadas. Este enfoque, no hay duda, es muy relevante, especialmente en los países emergentes con escasez de recursos para el desarrollo.
Los métodos prácticos, como el que aparece en este artículo, no son perfectos y sólo se puede aplicar a proyectos que tengan un número limitado de insumos importantes y que operan en una economía sin muchas ramificaciones (una economía más simple y local). La metodología debe ser adaptada a cada circunstancia, ya que las dificultades de la evaluación social de proyectos no es sólo teórica sino también práctica, pues se requieren datos que son aproximados. Los efectos directos mínimos se pueden evaluar con mayor propiedad que los efectos secundarios o inducidos, pero no se debe olvidar que este tipo de evaluación plantea muchos problemas conceptuales, metodológicos y estadísticos como bien lo señaló en su día Andre Bussery (1973: 47) y que los criterios para la selección son muchas veces juicios de valor que deben ser ponderados.

\section{Referencias Bibliográficas}

ASCANIO, Alfredo. 1988. El proyecto hotelero: una introducción a su evaluación. Estudios Turísticos, Madrid, n² 99, p.3-18.

BUSSERY, Andre. 1973. Evaluación de la rentabilidad económica de los proyectos productivos en los países en desarrollo. Industrialización y Productividad, New York: Naciones Unidas, boletín $\mathrm{n}^{2} 19$, p. 49-66.

FIGUEROLA P., Manuel. 1991. Elementos para el estudio de la economía de la empresa turística. Madrid: Síntesis.

FOSTER, Edward. 1980. Análisis coste-beneficio. Madrid: Instituto de Estudios Fiscales.

HERNÁNDEZ DÍAZ, Edgar Alfonso. 1985. Proyectos turísticos: formulación y evaluación. México: Trillas.

KLEIN, Alfred W. 1961. La productividad como criterio de inversión. México: Banco de México. 1957. Guía para investigaciones industriales y la auditoria de la productividad. Caracas: Ministerio de Fomento.

ONU. 1958. Manual de Proyectos de Desarrollo Económico.

REILLY, Park et. al. 1969. Decision-making through opinion analysis. Chemical Engineering, april 7, p. 122-129.

RIGGS, James. 1977. Ingeniería económica. México: McGraw-Hill.

VALERA, Rodrigo. 1969. Evaluación económica de inversiones. Bogotá: Norma

VILLA REAL, Arturo Infante. 1991. Evaluación financiera de proyectos de Inversión. Bogotá: Norma. (Ver, Cap. 14 sobre la evaluación social de proyectos).

Recibido em 30/05/2002

Aprobado em 18/08/2002 